\title{
The Impact of Salivary pH Value and Dental Caries Index on Periodontal Status among Adult Age Groups of Patients from Aseer Region, Saudi Arabia
}

\author{
Mohammed M. A. Abdullah Al-Abdaly ${ }^{*}$, Abdalkarim Ibrahim Mohammed Assiry² \\ ${ }^{1}$ Periodontics and Community Dental Sciences Department, College of Dentistry, King Khalid University, Abha, Saudi Arabia \\ ${ }^{2}$ College of Dentistry, King Khalid University, Abha, Saudi Arabia \\ Email: *malabdaly20@gmail.com
}

How to cite this paper: Al-Abdaly, M.M.A.A. and Assiry, A.I.M. (2020) The Impact of Salivary $\mathrm{pH}$ Value and Dental Caries Index on Periodontal Status among Adult Age Groups of Patients from Aseer Region, Saudi Arabia. Open Journal of Stomatology, 10, 199-209.

https://doi.org/10.4236/ojst.2020.107019

Received: June 23, 2020

Accepted: July 27, 2020

Published: July 30, 2020

Copyright $\odot 2020$ by author(s) and Scientific Research Publishing Inc. This work is licensed under the Creative Commons Attribution International License (CC BY 4.0).

http://creativecommons.org/licenses/by/4.0/

\begin{abstract}
Background: The patients' age is considered a modified risk factor that causes periodontal disease, dental caries, and their development. Objective: The present study was designed to evaluate the impact of salivary $\mathrm{pH}$ value and dental caries index on periodontal status among adult age groups of patients from Aseer region, Saudi Arabia. Methods: A cross-sectional analysis carried out in the college of dentistry, King Khalid University on 750 adult patients (400 males and 350 females). The adults patients were divided into three equal groups according to the patients' age: group I (20 - 30 years), group II (31 - 40 years), and group III (41 - 50 years). Plaque index (PLI), gingival index (GI), clinical attachment loss (CAL), and the dental caries index (DMFT) recorded as well as salivary $\mathrm{pH}$. All findings collected, then analyzed by an ANOVA test and the t-test. A p-value at $<0.05$ was considered a statistical significance level. Results: The clinical findings of the current study showed that there were statistically significant differences in the patients' age of both males and females. Moreover, there were statistically significant differences in GI. On the other hand, there were highly statistically significant differences in PLI and DMFS, but there were no significant differences in CAL of both males and females Moreover, there were no statistically significant differences in salivary $\mathrm{pH}$. Conclusion: We concluded that DMFT Index correlated to periodontal and oral health status and, it increased with the progression of the patient's age and can be used in the epidemiological evaluation of periodontal and oral health status.
\end{abstract}

\section{Keywords}

Adult Age Groups of Patients, Dental Caries Index, Periodontal Status, Salivary $\mathrm{pH}$ 


\section{Introduction}

Periodontal diseases and dental caries are considered the most common oral diseases, and their prevalence and effect on peoples remain more significant due to they can impact on the general health and cause tooth loss [1] [2]. Although the main etiologic factor of dental caries and periodontal diseases is dental plaque, other participated factors can impact oral health status [3] [4]. It is known that periodontal diseases exist in all age groups, but the adult population is more affected than other age groups without regard to region, genetics, gender, socioeconomic status, and education level [5].

The age is considered from the risk factors that influence the incidence, increase the prevalence and severity of periodontal disease due to continued exposure to the accumulation of dental plaque throughout the patient's life [6] [7]. Moreover, there were early studies in the world revealed that the oral health status and the patient's age were from the risk factors of dental caries and periodontal diseases and their effect either directly or indirectly where they noticed that chronic oral diseases like periodontal diseases, dental caries, temporomandibular disorders, and oral mucosal lesions are popular with an increase in the patients' age [8] [9] [10].

Saliva is a physical fluid act as a main method to determine and monitoring of oral mucosa [11]. The rate of salivary flow, changes of composition, the ability to buffer, and $\mathrm{pH}$ are fundamental factors in the identity of periodontal diseases, and tooth decay [12] [13].

On the other hand, DMFT index is an essential criterion for the evaluation of tooth decay and, it is applied to recognize the level of oral health [14] [15].

The Decayed, Missing and, Filled Teeth (DMFT) index has been applied in the world at least 70 years for evaluating the dental and oral health status. Moreover, this index is more significant in epidemiological studies of the community health status [16]. Through the application of this index in the monitoring and evaluation of oral health interventions within the community by the improvement of the programs and the policies that are related to this field [17] [18].

Over the last decade, there was significant interest in Saudi Arabia in the assessment of the effect of oral diseases on indicators of culture and socioeconomic status [19]. In college of dentistry, King Khalid University, there was no study carried out based on the impact of salivary $\mathrm{pH}$ value and dental caries index on periodontal status among adult age groups of patients from Aseer region, Saudi Arabia. Additionally, Saudi people aged 20 to $50 \mathrm{yr}$ olds are the most population productive groups in the society, so incorrect oral health can impact their daily actions.

It should be noted that there is a shortage of information about the oral health status, periodontal tissue status, and prevalence of dental caries in this Saudi population group. For these reasons, this study was designed to evaluate the impact of salivary $\mathrm{pH}$ value and dental caries index on periodontal status among adult age groups of patients from Aseer region, Saudi Arabia. This study, con- 
sequently, can help dental care providers, health policymakers, health care providers, and public health managers to helping the people in the Saudi community.

\section{Subjects and Methods}

\section{Subjects and Ethics statement}

This cross-sectional study was done between $2019-2020$ on 750 patients (400 males and 350 females) aged 20 - $50 \mathrm{yr}$ old and who was referred to periodontics clinics, College of Dentistry, King Khalid University. They were divided into three equal age groups: 20 - 30, $31-40$, and $41-50$ years. The study was done according to instructions of experimentation involving human samples in the Declaration of Helsinki and the proposal prepared according to the instructions of the scientific research committee, college of dentistry, King Khalid University. Before beginning the study, the goals of the study demonstrated to the participants and the written informed consent of participants obtained.

\section{Clinical oral examination}

The clinical examination of the participants was carried out by the investigators of this study.

\section{Inclusion criteria}

- Age 20 - 50 years.

- The patients without systemic diseases.

- The female participants were non-pregnant or breastfeeding women or women in menopausal status.

\section{The exclusion criteria}

- The patients with age under 20 years and above 50 years.

- The patients with systemic disease.

- The patients received antibiotics and periodontal treatment (in the previous 6 months).

- The patients with less than two teeth per sextant before to the study.

Examination of the patients' teeth:

Clinical examination of the patients' teeth was done to identify the comprehensive dental caries status according to the DMFT index. The clinical assessment was conducted according to WHO's diagnostic instructions with the use of a mouth mirror and a WHO probe (Hu Friedy, Chicago, IL) after drying the teeth in a lighted environment [20]. There were no radiographic examinations for the evaluation of dental caries.

\section{Periodontal Examination:}

For periodontal examination, PLI according to Silness and Loe [21], GI according to Loe and Silness [22], and CAL was conducted by using a mouth mirror and a standardized periodontal probe (Hu-Friedy Thin Williams Probe).

\section{Salivary $\mathrm{pH}$ measurement:}

We asked the participants to come between 9:00 am, and 11:00 am for the collection of saliva samples, and then we asked them to rinse their mouth with water (bottle) without drinking the water. Five minutes after the oral rinse, we asked them to spit the whole saliva into the collection tube $(5 \mathrm{ml}$ of saliva col- 
lected in a sterile $10 \mathrm{ml}$ tube). The salivary $\mathrm{pH}$ was directly measured with color-coded $\mathrm{pH}$ strips ( $\mathrm{pH}$ guide) to avoid any unwanted changes in the samples.

\section{Statistical Analysis}

An ANOVA test was used to statistical analysis of the clinical findings. The mean and standard deviation $( \pm \mathrm{SD})$ were recorded. $\mathrm{p}$ values $<0.05$ were considered statistically significant differences.

\section{Results}

The findings of the current study summarized in Tables 1-4 and Figures 1-4. The mean and standard deviation $( \pm \mathrm{SD})$ of the male participants' ages in group I, II and III are $29.26 \pm 4.14,39.39 \pm 14.28$ and $46.7 \pm 2.75$, whereas the mean and standard deviation $( \pm \mathrm{SD})$ of the female participants' ages in group I, II and III are $26 \pm 1.7,35.2 \pm 4.2$ and $43 \pm 9.3$. There were statistically significant differences in the age in the comparison between groups I, II, and III in both genders $(\mathrm{p}<0.05)$.

According to Tables 1-4 and Figures 2-4, there were highly statistically significant differences in the DMFT Index with all periodontal parameters $(\mathrm{p}=$ 0.001) except CAL in the comparison between groups I, II, and III where there were no statistically significant differences $(p>0.05)$ in both genders but there was no statistically significant difference in salivary $\mathrm{pH}$ in the comparison between groups I, II, and III in female participants $(\mathrm{p}>0.05)$ whereas there was a statistically significant difference in salivary $\mathrm{pH}$ in the comparison between groups I, II, and III in male participants ( $\mathrm{p}<0.05)$.

Moreover, there were differences in the mean of DMFT index, periodontal parameters, and salivary $\mathrm{pH}$ among the current study groups concerning gender also there was an increase in the mean of DMFT index and salivary $\mathrm{pH}$ with an increase the age and, there were differences in the mean of PLI, GI, and CAL between the age categories of both genders.

Table 1. The mean of patients' age groups according to the gender.

\begin{tabular}{|c|c|c|c|}
\hline \multicolumn{3}{|c|}{ Groups and gender } & \multirow{2}{*}{$\begin{array}{c}\text { Mean of Age } \pm \mathrm{SD}^{*} \\
29.26 \pm 4.14\end{array}$} \\
\hline \multirow{2}{*}{\multicolumn{2}{|c|}{$\mathrm{G}^{\pi} \mathrm{I}(20-30 \mathrm{ys})$}} & $M^{\#}$ & \\
\hline & & $\mathrm{F}^{\# \#}$ & $26 \pm 1.7$ \\
\hline \multirow{2}{*}{\multicolumn{2}{|c|}{ G II (31 - 40 ys) }} & M & $39.39 \pm 14.28$ \\
\hline & & $\mathrm{F}$ & $35.2 \pm 4.2$ \\
\hline \multirow{2}{*}{\multicolumn{2}{|c|}{ G III (41 - 50 ys) }} & M & $46.7 \pm 2.75$ \\
\hline & & $\mathrm{F}$ & $43 \pm 9.3$ \\
\hline \multirow{4}{*}{ ANOVA } & \multirow{2}{*}{$\mathbf{M}$} & p-value & $0.012^{\star}$ \\
\hline & & $\mathrm{F}^{* *}$ & 7.513 \\
\hline & \multirow{2}{*}{$\mathbf{F}$} & p-value & $0.031^{\star}$ \\
\hline & & $\mathrm{F}$ & 6.476 \\
\hline
\end{tabular}

${ }^{\star} \mathrm{p}$-value Statistically significant differences. ${ }^{\pi}$ Group, ${ }^{\#}$ Male, ${ }^{\# \#}$ Female. ${ }^{* \star F}$-value. 
Table 2. The mean of DMFT index according to the patients' gender.

\begin{tabular}{|c|c|c|c|}
\hline \multicolumn{3}{|c|}{ Groups and gender } & DMFT \\
\hline \multirow{2}{*}{$G^{\pi} I(20-30 y s)$} & & $\mathrm{M}^{\#}$ & $7.1 \pm 1.33$ \\
\hline & & $\mathrm{F}^{\# \#}$ & $8.2 \pm 4.7$ \\
\hline \multirow{2}{*}{ G II (31 - 40 ys) } & & M & $8.3 \pm 2.4$ \\
\hline & & F & $9.4 \pm 4.1$ \\
\hline \multirow{2}{*}{ G III (41 - 50 ys) } & & M & $8.4 \pm 3.4$ \\
\hline & & $\mathrm{F}$ & $9.8 \pm 4.6$ \\
\hline \multirow{4}{*}{ ANOVA } & \multirow{2}{*}{$\mathrm{M}$} & $\mathrm{p}$-value & $0.001^{*}$ \\
\hline & & $\mathrm{F}^{\star *}$ & 9.371 \\
\hline & \multirow{2}{*}{$\mathrm{F}$} & $\mathrm{p}$-value & $0.001^{*}$ \\
\hline & & $\mathrm{F}$ & 9.142 \\
\hline
\end{tabular}

${ }^{*}$ p-value Statistically significant differences. ${ }^{\pi}$ Group, ${ }^{*}$ Male, ${ }^{* *}$ Female. ${ }^{*}$ F-value. DMFT: The Decayed, Missing and Filled Teeth.

Table 3. The mean of periodontal parameters according to the patients' age and gender.

\begin{tabular}{|c|c|c|c|c|c|}
\hline \multicolumn{3}{|c|}{ Groups } & PLI & GI & CAL \\
\hline \multirow{2}{*}{\multicolumn{2}{|c|}{$G I^{\pi}(20-30 y s)$}} & $\mathrm{M}^{\#}$ & $1.9 \pm 0.42$ & $1.4 \pm 0.33$ & $3.06 \pm 1.69$ \\
\hline & & $\mathrm{F}^{\# \#}$ & $1.7 \pm 0.53$ & $1.514 \pm 0.46$ & $2.46 \pm 1.3$ \\
\hline \multirow{2}{*}{\multicolumn{2}{|c|}{ G II (31 - 40 ys) }} & M & $1.5 \pm 0.44$ & $1.3 \pm 0.51$ & $3.75 \pm 1.63$ \\
\hline & & $\mathrm{F}$ & $1.2 \pm 0.53$ & $1.466 \pm 0.416$ & $2.58 \pm 1.07$ \\
\hline \multirow{2}{*}{\multicolumn{2}{|c|}{ G III (41 - 50 ys) }} & M & $1.6 \pm 0.81$ & $1.7 \pm 0.73$ & $3.24 \pm 1.95$ \\
\hline & & $\mathrm{F}$ & $1.4 \pm 0.56$ & $1.343 \pm 0.431$ & $2.49 \pm 1.7$ \\
\hline \multirow{4}{*}{ ANOVA } & \multirow{2}{*}{ M } & $\mathrm{p}$-value & $0.001^{*}$ & $0.012^{*}$ & 0.854 \\
\hline & & $\mathrm{F}^{\star *}$ & 6.465 & 2.256 & 1.757 \\
\hline & \multirow{2}{*}{$\mathrm{F}$} & $\mathrm{p}$-value & $0.001^{\star}$ & 0.022 & 0.943 \\
\hline & & $\mathrm{F}$ & 6.465 & 1.285 & 1.529 \\
\hline
\end{tabular}

${ }^{*}$ p-value Statistically significant differences. ${ }^{\pi}$ Group, ${ }^{*}$ Male, ${ }^{* *}$ Female. ${ }^{* * F-v a l u e . ~ P L I: ~ p l a q u e ~ i n d e x, ~ G I: ~ G i n-~}$ gival index, CAL: Clinical attachment loss.

Table 4. The mean of salivary $\mathrm{pH}$ according to the patients' age and gender.

\begin{tabular}{|c|c|c|}
\hline \multicolumn{2}{|c|}{ Groups and gender } & \multirow{2}{*}{$\begin{array}{l}\text { Salivary } \mathrm{pH} \\
7.15 \pm 0.34\end{array}$} \\
\hline \multirow{2}{*}{$\mathrm{G}^{\pi} \mathrm{I}(20-30 \mathrm{ys})$} & $\mathrm{M}^{\#}$ & \\
\hline & $\mathrm{F}^{\# \#}$ & $6.72 \pm 0.44$ \\
\hline \multirow{2}{*}{ G II (31 - 40 ys) } & M & $7.35 \pm 0.38$ \\
\hline & $\mathrm{F}$ & $6.77 \pm 0.36$ \\
\hline \multirow{2}{*}{ G III (41 - 50 ys) } & M & $7.83 \pm 0.12$ \\
\hline & $\mathrm{F}$ & $6.77 \pm 0.32$ \\
\hline \multirow{4}{*}{ ANOVA } & $\mathrm{p}$-value & $0.035^{\star}$ \\
\hline & $\mathrm{F}^{* *}$ & 9.257 \\
\hline & p-value & 0.77 \\
\hline & $\mathrm{F}$ & 1.934 \\
\hline
\end{tabular}

${ }^{*}$ p-value Statistically significant differences. ${ }^{\pi} \mathrm{Group},{ }^{*}$ Male, ${ }^{* *}$ Female. ${ }^{* *} \mathrm{~F}$-value. 


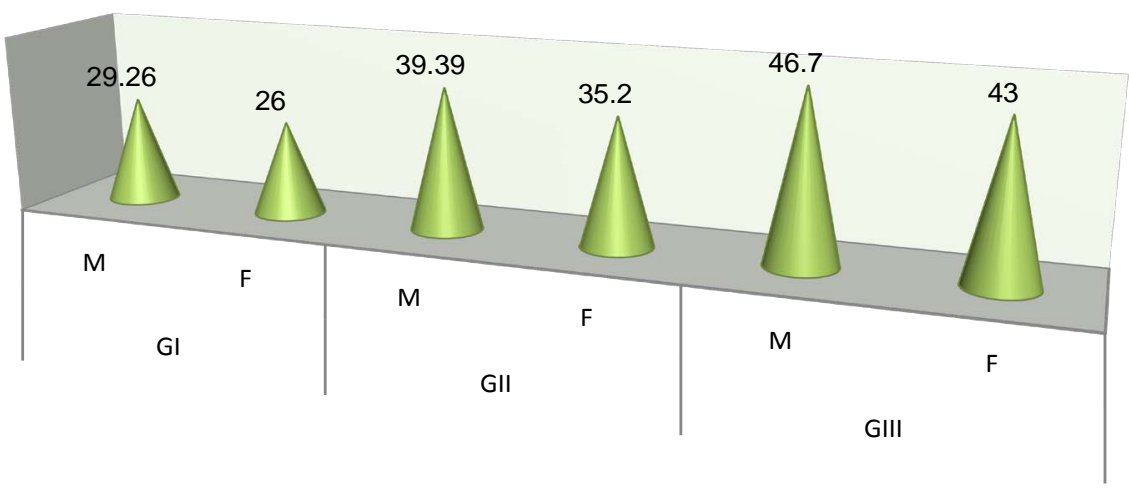

Figure 1. Mean of patients' age groups.

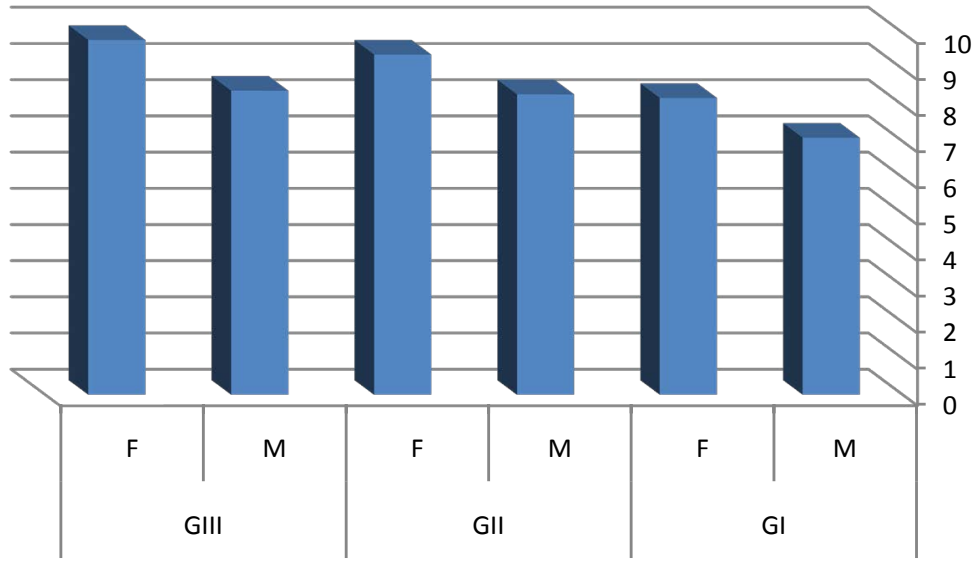

Figure 2. DMFT index.

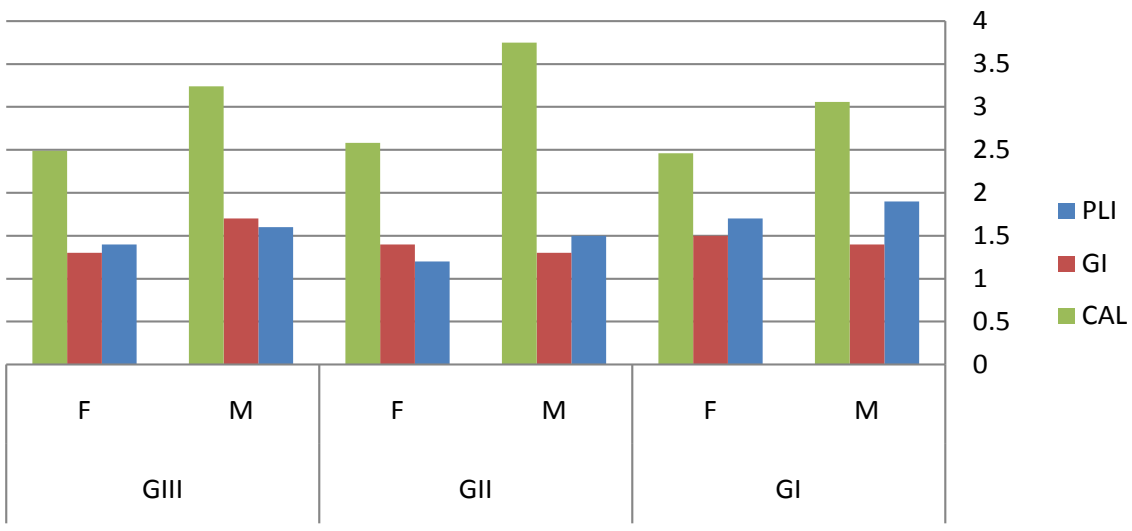

Figure 3. Periodontal parameters.

On the other hand, Table 3 and Figure 3 revealed that the mean of PLI in male and female in group I more than group II and III whereas the mean of GI in group III more than group I and II and the mean of CAL in group II more than group I and III in both genders.

Generally, The mean of PLI and CAL in males higher than females and the mean of GI in females higher than males in all groups except group III where the mean of GI in males more than females. 


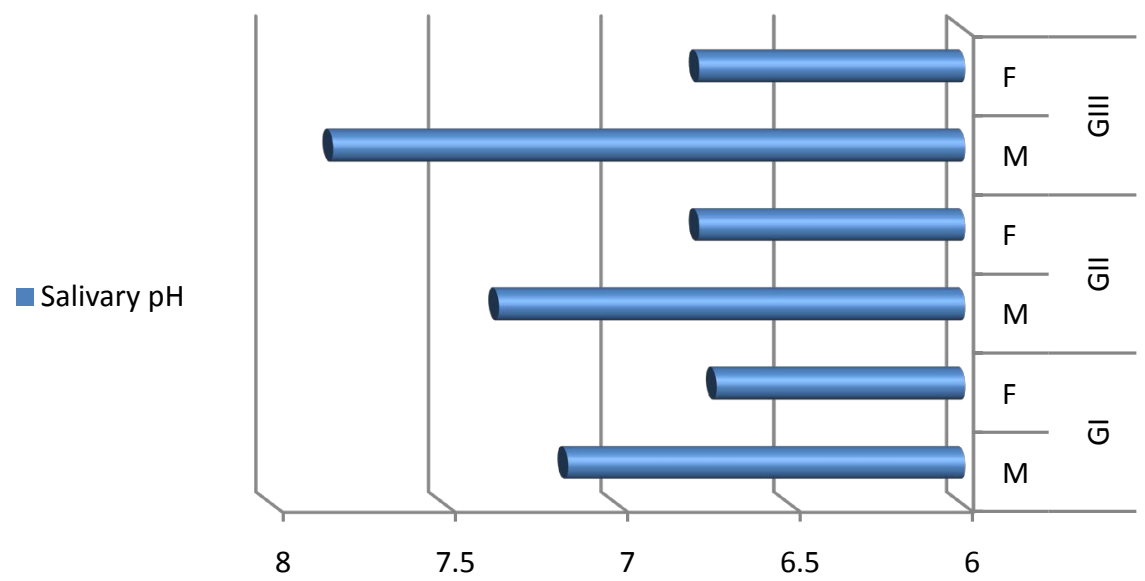

Figure 4. Salivary $\mathrm{pH}$.

\section{Discussion}

The present study revealed a high incidence of periodontal diseases and the decayed, missing, and filled teeth among the participants. Consequently, its results will help to increase oral health awareness and to the enhancement of good oral health. Furthermore, to apply prevention and treatment methods to decrease decayed and missing teeth also, this study results may be beneficial in the assessment and planning of periodontal and oral health programs in the past and the future [23].

Saliva is a biofluid used as an essential diagnostic method to identify some oral and systemic diseases and prediction of its therapy outcome [24]. In this study, there is an association between an increase of salivary $\mathrm{pH}$ and a DMFT index with an increase of age. The average of salivary $\mathrm{pH}$ value in this study was within the normal average with significant differences between males and not with females, maybe due to that the all participants in the study were without systemic disease [25]. These findings are consistent with the findings of Bnoosh's study [26].

And as a result of that, this study revealed that salivary $\mathrm{pH}$, the patients' age, and DMFT Index value was considered significant factors for the assessment of periodontal and oral health status. This finding is consistent with the results of other studies [27].

On the other hand, there was an increase in salivary $\mathrm{pH}$ value among the patients with generalized periodontitis in the study of Baliga et al. Furthermore, Galgut detected that was no link between salivary $\mathrm{pH}$ value and increase gingivitis, which was more with pocket formation [28] [29]. According to the results of the study of Flores-de-Jacoby et al., There were $41 \%$ and $51 \%$ of participants in the older age group were affected with moderate and severe periodontal diseases whereas $50 \%$ young age group were affected with moderate periodontal diseases [30]. Consistent with the current study where participants in the older age group and young age group were affected with moderate periodontal diseases in males and females. Moreover, these results in agreement with the findings of a non- 
representative Saudi study done in 2008 that revealed that $37.4 \%$ of participants were affected by shallow pockets and, there were not present deep pockets in the clinical findings [31]. The patients of all age groups in this study had a moderate oral hygiene status, different than the results of other studies that appeared more than $60 \%$ of the patients had a bad oral hygiene status [32].

In the present study, there was significantly higher on the DMFS index among females compared to males. These results are consistent with the results of other Saudi study [33]. This may be attributed to the changes in hormonal levels and the earlier eruption of permanent teeth in females. Also, according to a meta-analysis Saudi study, there was a high percentage of DMFT index of all age groups in the different regions of Saudi Arabia [34], which is harmonious with the results of the current study and other studies conducted in other regions in Saudi Arabia [35] [36]. In the present study, there was a significant link between the patients' age and DMFS index, where these findings were in older patients higher than younger ones. This was similar to another study [37].

\section{Strength and Limitations}

There were limitations of the current study where it included the assessment the effect of salivary $\mathrm{pH}$ value and dental caries index on periodontal and oral health status without evaluation of the sociodemographic variables such as patients' education level, patients' economic status. Furthermore, the present study exhibits the periodontal and oral health status and does not evaluate the other personal reasons that may be impacting on periodontal and oral health. Another limitation of this study was that these findings included just participants who came to the College of Dentistry, King Khalid University not all people of the Aseer region, and other Saudi regions.

\section{Conclusion}

We concluded that salivary $\mathrm{pH}$, the severity of dental caries, and periodontal diseases increased with aging. Nevertheless, we need to collect and evaluate other data, such as sociodemographic factors to identify efficient oral health planning strategies in the Aseer region, Saudi Arabia and we concluded also that the importance of an evaluating the effect of patients' age on salivary $\mathrm{pH}$ value, dental caries, and periodontal and oral health as a part of community oral health programs.

\section{Acknowledgements}

The authors would like to thank the staff faculty members in the outpatient clinics of a college of dentistry, King Khalid University for their facilitating, and helping in the collection of data.

\section{Conflicts of Interest}

The authors declare no conflicts of interest regarding the publication of this paper. 


\section{References}

[1] Barmes, D.E. (1999) A Global View of Oral Diseases: Today and Tomorrow. Community Dentistry and Oral Epidemiology, 27, 2-7.

https://doi.org/10.1111/j.1600-0528.1999.tb01985.x

[2] Heilmann, A., Tsakos, G. and Watt, R.G. (2015) Oral Health over the Life Course. In: Burton-Jeangros, C., Cullati, S., Sacker, A. and Blane, D., Eds., A Life Course Perspective on Health Trajectories and Transitions. Life Course Research and Social Policies, Springer, Cham, 39-59. https://doi.org/10.1007/978-3-319-20484-0_3

[3] Villalobos-Rodelo, J.J., Medina-Solis, C.E., Maupome, G., et al. (2007) Socioeconomic and Sociodemographic Variable Associated with Oral Hygiene Status in Mexican School Children Aged 6 to 12 Years. Journal of Periodontology, 78, 816-822. https://doi.org/10.1902/jop.2007.060324

[4] Bollen, C.M., Papaioanno, W., Van Eldere, J., et al. (1998) The Influence of Abutment Surface Roughness on Plaque Accumulation and Peri-Implant Mucositis. Clinical Oral Implants Research, 7, 201-211. https://doi.org/10.1034/j.1600-0501.1996.070302.x

[5] El-Qaderi, S.S. and Quteish Ta'ani, D. (2004) Assessment of Periodontal Knowledge and Periodontal Status of an Adult Population in Jordan. International Journal of Dental Hygiene, 2, 132-136. https://doi.org/10.1111/j.1601-5037.2004.00080.x

[6] Savage, A., Eaton, K.A., Moles, D.R. and Needlemen, I. (2009) A Systematic Review of Definitions of Periodontitis and Methods That Have Been Used to Identify This Disease. Journal of Clinical Periodontology, 36, 458-467.

https://doi.org/10.1111/j.1600-051X.2009.01408.x

[7] Bhadbhade, S. (2015) Aging and Periodontium. International Journal of Dentistry and Oral Science, 2, 79-83. https://doi.org/10.19070/2377-8075-1500017

[8] Damyanov, N.D., Witter, D.J., Bronkhorst, E.M. and Creugers, N.H. (2012) Dental Status and Associated Factors in a Dentate Adult Population in Bulgaria: A Cross-Sectional Survey. International Journal of Dentistry, 2012, Article ID: 578401. https://doi.org/10.1155/2012/578401

[9] Singh, M.L. and Papas, A. (2014) Oral Implications of Polypharmacy in the Elderly. Dental Clinics of North America, 58, 783-796. https://doi.org/10.1016/j.cden.2014.07.004

[10] De Oliveira, T.C., Da Silva, D.A., Leite De Freitas, Y.N., Da Silva, R.L., Pegado, C.P. and De Lima, K.C. (2013) Socio Demographic Factors and Oral Health Conditions in the Elderly: A Population Based Study. Archives of Gerontology and Geriatrics, 57, 389-397. https://doi.org/10.1016/j.archger.2013.05.004

[11] Fabian, T.K., Fejerdy, P. and Csermely, P. (2008) Chemical Biology of Saliva in Health and Disease. In: Begley, T.P., Ed., Wiley Encyclopedia of Chemical Biology, John Wiley and Sons, New York, USA, 1-9.

https://doi.org/10.1002/9780470048672.wecb643

[12] Shannon, I.L., Kilgore, W.I. and Terry, J.M. (1969) Relation of Parotid Flow Rate, Sodium, Potassium, and Chloride Concentrations to Caries Experience. Journal of Oral Medicine, 24, 3-5.

[13] Animireddy, D., Reddy Bekkem, V.T., Vallala, P., Kotha, S.B., Ankireddy, S. and Mohammad, N. (2014) Evaluation of pH, Buffering Capacity, Viscosity and Flow Rate Levels of Saliva in Caries-Free, Minimal Caries and Nursing Caries Children: an in Vivo Study. Contemporary Clinical Dentistry, 5, 324-328.

https://doi.org/10.4103/0976-237X.137931 
[14] Babaei Hatkehlouei, M., Tari, H., Goudarzian, A.H. and Hali, H. (2017) Decayed, Missing, and Filled Teeth (DMFT) Index among First-Grade Elementary Students in Mazandaran Province, Northern Iran. International Journal of Pediatrics, 5, 5069-5077.

[15] Murray Thomson, W. (2014) Epidemiology of Oral Health Conditions in Older People. Gerodontology, 31, 9-16. https://doi.org/10.1111/ger.12085

[16] Broadbent, J.M. and Thomson, W.M. (2005) For Debate: Problems with the DMF Index Pertinent to Dental Caries Data Analysis. Community Dentistry and Oral Epidemiology, 33, 400-409. https://doi.org/10.1111/j.1600-0528.2005.00259.x

[17] Marthaler, T.M. (2004) Changes in Dental Caries 1953-2003. Caries Research, 38, 173-181. https://doi.org/10.1159/000077752

[18] Nadanovsky, P. and Sheiham, A. (1995) Relative Contribution of Dental Services to the Changes in Caries Levels of 12-Year-Old Children in 18 Industrialized Countries in the 1970s and Early 1980s. Community Dentistry and Oral Epidemiology, 23, 331-339. https://doi.org/10.1111/j.1600-0528.1995.tb00258.x

[19] Al-Shammery, A.R. (1999) Caries Experience of Urban and Rural Children in Saudi Arabia. Journal of Public Health Dentistry, 59, 60-64. https://doi.org/10.1111/j.1752-7325.1999.tb03236.x

[20] WHO (1997) Oral Health Surveys: Basic Methods. 4th Edition, World Health Organization, Geneva.

[21] Silness, J. and Loe, H. (1964) Periodontal Disease in Pregnancy. II. Correlation between Oral Hygiene and Periodontal Condtion. Acta Odontologica Scandinavica, 22, 121-135. https://doi.org/10.3109/00016356408993968

[22] Loe, H. and Silness, J. (1963) Periodontal Disease in Pregnancy. I. Prevalence and Severity. Acta Odontologica Scandinavica, 21, 533-551.

https://doi.org/10.3109/00016356309011240

[23] Provenza, D.V. (1986) Textbook of Oral Histology, Inheritance and Development. 2nd Edition, Lea and Gebinger, Philadelphia.

[24] Corstjens, P. (2008) Point-of-Care Diagnostics for Infectious Diseases. In: Wong D.T., Ed., Saliva Diagnostics, Wiley-Blackwell, Ames, 243-254.

[25] Baliga, S., Mugliker, S. and Kal, R. (2013) Salivary pH: A Diagnostic Biomarker. Journal of Indian Society Periodontology, 17, 461-465. https://doi.org/10.4103/0972-124X.118317

[26] Bnoosh, S. (2015) Some Salivary Parameters in Relation to Dental Caries-Experiences. Kirkuk University Journal, 10, 292-303.

[27] Petersen, P.E. (2008) The World Oral Health Report 2003: Continuous Improvement of Oral Health in the 21st Century-The Approach of the WHO Global Oral Health Program. Community Dentistry and Oral Epidemiology, 31, 3-24. https://doi.org/10.1046/j..2003.com122.x

[28] Baliga, S., Muglikar, S. and Kale, R. (2013) Salivary pH: A Diagnostic Biomarker. Journal of Indian Society of Periodontology, 17, 461-465. https://doi.org/10.4103/0972-124X.118317

[29] Galgut, P.N. (2001) The Relevance of $\mathrm{pH}$ to Gingivitis and Periodontitis. Journal of the International Academy of Periodontology, 3, 61-67.

[30] Flores-de-Jacoby, L., Bruchmann, S., Mengel, R. and Zafiropoulos, G.G. (1991) Periodontal Conditions in Rio de Janeiro City (Brazil) Using the CPITN. Community Dentistry and Oral Epidemiology, 19, 127-128.

https://doi.org/10.1111/j.1600-0528.1991.tb00127.x 
[31] Farsi, N., Al Amoudi, N., Farsi, J., et al. (2008) Periodontal Health and Its Relationship with Salivary Factors among Different Age Groups in a Saudi Population. Oral Health and Preventive Dentistry, 6, 147-154.

[32] Broadbent, J.M., Thomson, W.M., Boyens, J.V. and Poulton, R. (2011) Dental Plaque and Oral Health during the First 32 Years of Life. The Journal of the American Dental Association, 142, 415-426.

https://doi.org/10.14219/jada.archive.2011.0197

[33] Hassan, A., Amer, H., Mousa, A. and Gaznawi, H. (2005) Prevalence and intensity of Dental Caries among School Students in Jeddah City. Egyptian Dental Journal, 51, 1427-1432.

[34] Khan, S.Q., Khan, N.B. and Arrejaie, A.S. (2013) Dental Caries. A Meta Analysis on a Saudi Population. Saudi Medical Journal, 34, 744-749.

[35] Qutob, A.F. (2009) A Needs-Based Approach for Health Human Resources Planning for Dentistry in Jeddah, Saudi Arabia. Doctoral Dissertation, University of Toronto, Toronto.

[36] Magbool, G. (1992) Prevalence of Dental Caries in School Children in Al-Khobar, Saudi Arabia. ASDC Journal of Dentistry for Children, 59, 384-386.

[37] Lee, H.Y., Choi, Y.H., Park, H.W. and Lee, S.G. (2012) Changing Patterns in the Association between Regional Socio-Economic Context and Dental Caries Experience According to Gender and Age: A Multilevel Study in Korean Adults. International Journal of Health Geographics, 11, Article No. 30.

https://doi.org/10.1186/1476-072X-11-30 